\title{
Adverse Event Ongoing
}

National Cancer Institute

\section{Source}

National Cancer Institute. Adverse Event Ongoing. NCI Thesaurus. Code C83051.

An indication or description that an adverse event is continuing. 